\title{
Maintainability Risk Factors of Flat Roofs in Multi-Storey Buildings in Sri Lanka
}

\section{NayantharaDe Silva,Malik Ranasinghe and R. Rameezdeen}

\begin{abstract}
The research into the issue of maintainability of multi-storey buildings in Sri Lanka is still in its adolescent stage. One of the critical building elements that requires immediate attention for maintainability is flat roof areas. The flat roofs are often subjected to alternate drying and wetting cycles under tropical conditions, causing many defects and subsequent deterioration when proper detailing related to design, construction and maintenance actions are lacking. The inherent risks of maintainability of the buildings can be identified by analyzing their defects causing factors. In this research, 12 such risk factors related to the maintainability of flat roofs were identified. Further, a scoring system using Artificial Neural Networks (ANN) is developed to forecast the level of maintainability, which is projected, based on risk analysis. The level of maintainability of a typical flat roof is shown as $51 \%$. The risk factors are also prioritized to give guidance.
\end{abstract}

Keywords: Maintainability, Risk analysis, Sensitivity analysis, Flat roofs, Neural Networks

\section{Introduction}

The concept of maintainability was initiated by military services in USA in the 1950s [1] as well as in UK in the 1960s [2-3] and then broadened all over the world. Currently it generates a sufficient portion of the total construction output all over the world especially in developed countries. This is due to the fact that the maintenance budgets are increased significantly due to various factors like poor designs, inferior construction and poor planning for maintenance. In certain instances the maintenance cost resulting from the above factors can even amount to a half of the total cost of the original construction itself [4]. These increased costs are reported due to the growing complexity of buildings, lack of integration between different stages such as design; construction and maintenance, and budget and time constraints [5-6]. According to the data available from department of Census and Statistics in Sri Lanka, the proportion of the maintenar :e cost is around $17 \%$ of the total expenditure on building construction related activities [7].

However, in general practice, there is 1.) budget allocation for the maintenance in most of the buildings in Sri Lanka. This becomes a serious issue when more than one client is occupying a single property (eg. apartments or condominiums) because individual owners may be reluctant to take responsibilities or use their own money when a common area like roof incurs a problem. With the lack of funding allocated for the maintenance, rapidly mushrooming condominiums in Colombo, and its suburbs and other cities in Sri Lanka may soon become a heavy strain to the facilities managers and the users if this is not properly handled.

In the Sri Lankan construction industry, the early allocation of necessary provisions towards future maintainability is not considered as a common practice. This practice is likely to cause serious issues in the near future especially with respect to the large numbers of apartment buildings, condominiums and shopping complexes. As a result, these buildings are likely to suffer from poor maintenance causing significant issues to their owners, users, managers and regulatory and safety authorities.

\section{Implications of Poor Maintainability Practices}

Many researchers have discussed the generators or causes of maintainability problems from deficiencies under three main divisions [5, 8-17] as,

Mrs. Nayanthara De Silva, BSc Eng., MSc (Building), Senior Lecturer, Dept. of Building Economics, University of Moratuwa

Eng. (Prof.) Malik Ranasinghe, BSc Eng., MASc, PhD,

CEng, FIE(Sri Lanka), Vice Chancellor, University of Moratuwa

Dr. $R$ Rameezdeen, BSc QS, MEng(Const.Mgt.) PhD, AAIQS, AIQS(SL), Head, Dept. of Building Economics, University of Moratuwa 
- $\quad$ Causes initiated during the design stage.

- Causes initiated during the construction stage.

- Causes initiated during the usage stage (adhoc maintenance practices)

It is however identified that all these deficiencies can be planned for avoidance or control during the design stage. Owing to this, it requires taking an integrated approach throughout the design, construction and maintenance phases of a building [18]. Unfortunately in the normal contract system, designers of buildings rarely have long term interest in the buildings they produced; hence, they become divorced from the maintainability problems that follow from their poor involvement. On the other hand, involvement of a facility manager or a maintenance manager during the design process and the construction process is almost negligible in the local industry.

Therefore under these prevailing circumstances, there are many existing risks. The implications of buildings, from such risks could be economic implications, prestige, interest of public and users and, effect on material. Economic implications can be caused from the increased maintenance budget due to deficiencies arising during the above three stages. A large portion of this budget may be used for repairs or replacements of components due the rapid deterioration under the prevailing conditions. The rate of deterioration will depend on the sensitivity of the component for a deterioration agent (risks parameter) and the quantity of a deterioration agent at the location of a component [19]. In this research, 721 defects/problems related to flat roofs of 50 buildings arisen from above causes were observed and listed into 16 major types (Table $1)$.

\section{Research Method}

$3.1 \quad$ Field Survey

Phase 1: Fifty multi-storey buildings (above 4 storeys) were randomly selected to identify maintainability problems of flat roofs. These compromised residential buildings (46\%), commercial buildings (30\%) and office buildings (24\%). The age group of the building sample is spanned from 5 years to 25 years. A condition survey was carried out to explore the existing defects and their extent. In this survey, the conditions were clearly defined with the aid of photographs to illustrate very severe, severe, moderate, law, very low conditions of building defects. This survey was conducted during the monsoon season; June-July, in order to capture more problems caused under the tropical environment.

The defects identified from the condition survey were analyzed in detail to identify their causes. The maintenance teams' knowledge and experiences in this field were elicited in this exercise. However, for those buildings in which a permanent maintenance team was not available, this exercise was conducted with the help of residents and experts from other buildings. Further, a clear picture of the problem was shown to these experts with the aid of photographs and in certain cases, with small video clips of the sites.

Phase 2: Residence managers or maintenance managers were interviewed to elicit the existing risk conditions of their buildings. Structured survey forms were used in this exercise.

Phase 3: The actual maintenance costs of these buildings were worked out from the rates of cleaning and operational costs obtained from the maintenance managers. Further, different rates for retrofitting of those identified defects were obtained from individual quantity surveyors and several organizations in order to calculate retrofitting costs of building where these values were not available.

\subsection{Prototype Scoring System}

This model is developed on the basis of maintainability risk analysis. The maintainability risk is evaluated through the causes of problems and defects occurring during the maintenance stage. The impact of these problems and defects are analyzed based on the loss of performance of the building by many authors [20-22]. Similarly, some researchers have measured the magnitude of building maintenance by using cost as the criterion [23-24]. Further, Chew et al [25] have developed a prototype scoring system to evaluate the level of maintainability of buildings at the design stage, combining these two approaches.

In this research, the framework of the scoring system developed by Chew et al., [25] was used to develop a prototype model for flat roof maintainability. Chew's framework was used here due to its relevance under tropical conditions. Artificial Neural Network technique was used to develop the model. Defect/problem causing factors identified from the field survey were taken as inputs (i.e. maintainability risk factors) for the model. The output of the model was worked out based on the deviation from the optimum level of maintainability, which was mathematically expressed by Chew et al., [25]. 
Table 1: Flat Roof Defects

\begin{tabular}{|c|c|c|c|c|c|c|c|}
\hline$\stackrel{o}{z}^{2}$ & $\frac{\frac{n}{0}}{\frac{0}{0}}$ & 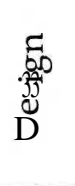 & 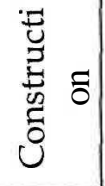 & 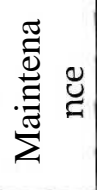 & 离 & 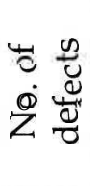 & 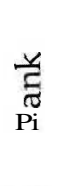 \\
\hline 01 & Splitting & $*$ & & & $*$ & 64 & 3 \\
\hline 02 & Blistering of paint film & $*$ & & & $*$ & 58 & 4 \\
\hline 03 & Water pounding & & & & & 56 & 6 \\
\hline 04 & Slippage & & & & $*$ & 20 & 16 \\
\hline 05 & Crocodiling or Alligatoring & $*$ & & & * & 33 & 12 \\
\hline 06 & Gravel scouring & & & * & * & 50 & 7 \\
\hline 07 & $\begin{array}{l}\text { Blistering of waterproofing -membrane } \\
\text { system }\end{array}$ & & & & & 34 & 11 \\
\hline 08 & Bulging effect of sealant & $*$ & & & $*$ & 32 & 14 \\
\hline 09 & $\begin{array}{lccc}\begin{array}{l}\text { Adhesive failure of sealant from } \\
\text { biological growth }\end{array} & & & \\
\end{array}$ & & & & $*$ & 32 & 14 \\
\hline 10 & Joint failure & $*$ & & & $*$ & 43 & 8 \\
\hline 11 & Crack on roof slab & * & & & $*$ & 66 & 1 \\
\hline 12 & Deflection of roof slab & $*$ & & & & 58 & 4 \\
\hline 13 & Chokage & & & $*$ & & 66 & 1 \\
\hline 14 & Crack at roof drainage & & & & * & 38 & 9 \\
\hline 15 & Water leakage through the slab & $*$ & & & & 38 & 9 \\
\hline 16 & Mechanical damage & & & & & 33 & 12 \\
\hline
\end{tabular}

\section{Flat Roof Maintainability Risk Factors}

Maintainability of buildings is more or less a localized issue that depends on several local factors like climatic conditions, architectural practices, construction materials and techniques etc. and hence it is important to identify significant risk factors confined to existing conditions. However, the maintainability risks of flat roofs could be looked at under three main stages:

\section{Design Risk}

- Causes initiated during the design stage water-tightness, stress accommodation, water flow control, accessibility, environment related and materials' performance, etc.,

2. Construction Risk

- Causes initiated during the construction stage - quality of construction

3. Maintenance Risk

- Causes initiated during the maintenance stage - quality of maintenance

Under above three stages, 12 significant risk factors were identified for roof's maintainability.
These risk factors were evaluated using 18 parameters (Table 2).

\section{Risk Analysis}

Once significant risk factors have been identified, they can be analysed in depth. Such risk analysis is concerned with the severity of each risk attribute to maintenance life cycle cost. Over the past years, several formal techniques have been developed to facilitate the risk analysis. They are ranged from simple techniques such as elementary risk analysis up to more sophisticated techniques that involve modern concepts like application of expert systems and neural networks [26]. However, the inherent complexity of the maintainability, sophisticated expert systems like neural networks are useful tools to model the underlying function to grade the level of maintainability confined in a design [27-29]

In this model, risks parameters are converted into a homogeneous scale using a discrete scale (rating) between 1 and 5 to represent the level of risk for each factor. A value closer to 1 signifies great risk while a value closer to 5 represents a negligible risk. 
Table 2: Flat Roof Maintainability Risk Factors

\begin{tabular}{|c|c|c|}
\hline (1) Risk Factors & (2) Parameters & (3) Elements \\
\hline 1. Detailing of concrete slab & $\begin{array}{l}\text { 1. Strength } \\
\text { 2. } \text { Concrete cover } \\
\text { 3. } \text { Joint detailing }\end{array}$ & $\begin{array}{l}\text { Adherence to typical design / } \\
\text { and detailing }\end{array}$ \\
\hline $\begin{array}{l}\text { 2. Waterproofing system } \\
\text { selection }\end{array}$ & $\begin{array}{ll}\text { 4. } & \text { Suitability } \\
\text { 5. } & \text { Reliability }\end{array}$ & * Type of protection mechanism \\
\hline 3. Waterproofing detail & $\begin{array}{l}\text { 6. Design/Application detail - } \\
\text { joints, penetrations, } \\
\text { projections, etc., }\end{array}$ & $\begin{array}{l}\text { - I* Adherence to typical design / } \\
\text { application considerations and } \\
\text { detailing }\end{array}$ \\
\hline $\begin{array}{l}\text { 4. External drainage system } \\
\text { selection }\end{array}$ & 7. Type of system & \\
\hline $\begin{array}{l}\text { 5. External drainage system } \\
\text { details }\end{array}$ & 8. Sufficient capacity & \\
\hline $\begin{array}{l}\text { 6. External drainage system } \\
\text { maintainability }\end{array}$ & $\begin{array}{l}\text { 9. Extent of maintenance work } \\
\text { requirements. }\end{array}$ & \\
\hline 7. Material selection & 10. Durability & $\therefore \quad$ Life span \\
\hline 8. Material detail & 11. Sustainability & * Testing requirements \\
\hline 9. Material maintainability & $\begin{array}{l}\text { 12. Cleanability } \\
\text { 13. Inspection }\end{array}$ & $\begin{array}{l}* \quad \text { Cleaning requirement } \\
* \quad \text { Inspection requirement }\end{array}$ \\
\hline 10. Construction quality & 14. Workmanship quality & $\begin{array}{ll}* & \text { Financial } \\
* & \text { Technical } \\
* & \text { Human resource } \\
* & \text { Quality management }\end{array}$ \\
\hline 11. Maintenance practice & $\begin{array}{l}\text { 15. Method } \\
\text { 16. Efficiency }\end{array}$ & $\begin{array}{l}\text { * } \begin{array}{l}\text { Maintenance inspections, } \\
\text { equipments and chemical used } \\
\text { for cleaning }\end{array} \\
* \quad \begin{array}{l}\text { Frequencies of inspection and } \\
\text { cleaning cycles }\end{array}\end{array}$ \\
\hline 12. Building profile & $\begin{array}{l}\text { 17. Age } \\
\text { 18. Height }\end{array}$ & \\
\hline
\end{tabular}

\subsection{Risk of Roof Slab Failures}

Failure to achieve dense, sound and homogeneous concrete slab could lead to many defects increasing maintainability problems of flat roofs. Owing to this, the selection of proper concrete mix design, concrete cover, joint detailing can be considered during the design stage to achieve a good performing structure. Having said that, the grading for the performance of a slab ( $1^{\text {st }}$ risk factor) was established considering the above parameters (i.e. concrete mix design, concrete cover, joint detailing, etc.), using 1-5 scale.

\subsection{Risk of Waterproofing Failures}

The failure to achieve the water tightness is the most significant problem in flat roofs maintainability. The water tightness of a flat roof relies mainly on the integrity of the structure, waterproofing design detailing including the adequacy of waterproofing over penetrations, projections, and detailing over joints. For the selection of waterproofing systems determines the degree of protection required while the method of construction limits the type of protection systems to be chosen ( $2^{\text {nd }}$ risk factor). The quality of application also determines the eventual degree of water tightness attained. With the proper 
selection of the waterproofing system, appropriate design detailing and sound workmanship during application, the water tightness in flat roof could be improved and prolonged.

The waterproofing detailing is another critical factor in achieving the water tightness. In this regard, joints are vulnerable points prone to water ingress and should be paid greater attention in providing detailing over joints, penetrations, and even projections. Proper detailing in the design will minimize the risk of such lines of weakness while inadequate detailing in the design will cause great risk and results in repetitive occurrence of defects at these critical points (3rd risk factor).

\subsection{Risk of External Drainage System Failures}

Although the roof structure must be designed to prevent any ingress of surface runoff, this can not be completely avoided. As such, there is a need for a good flow drainage system to ensure that the roof is protected from this external source of water $\left(4^{\text {th }}\right.$ risk factor $)$. The surface drainage system should adhere to the local design guidelines for efficient removal of the rain water run off from the structure $\left(5^{\text {th }}\right.$ risk factor $)$. Being a tropical country with frequent rainstorms, the roof requires more regular care and maintenance to the drainage systems to prevent pipe clogging, overflows, leaks and discharge interferences. Therefore the extent of maintainability of such systems would be equally important as its details. In this regard, accessibility for maintenance is identified as the most important consideration $\left(6^{\text {th }}\right.$ risk factor).

\subsection{Risk of Material}

With good workmanship, appropriate material detailing and with proper maintenance, a selected material should perform up to its expected lifespan. However, the actual lifespan and performance can be undermined by the interactions with other materials in the structure. Further, careful consideration is needed to ensure the durability of the selected material under its prevailing environment, so that the overall lifespan would not be compromised due to premature failures $\left(7^{\text {th }}\right.$ risk factor $)$.

The selected roof materials should have the ability to resist defects resulting from external factors such as moisture, rain, chemicals, etc., in order to perform its intended function through its design life. The inherent properties of materials determine the level of sustainability of their functional purposes under various exposure conditions. Therefore performance of materials under such conditions can be assessed through testing and approvals for properties pertinent to maintainability $\left(8^{\text {th }}\right.$ risk factor). Here, materials can be tested or checked under local standards, manuals or reputable international standards for common consequences given by the tropical climate as, (1) resistance to cracking, (2) resistance to dampness, (3) resistance to chipping, (4) resistance to staining such as biological growth, sealant, and staining caused by incompatibility of material interfaces, and (5) resistance to chemical attacks.

During the service life, the frequency of maintenance cycles that has to be required yearly for maintaining selected materials for the structure represents a large proportion of the maintenance budget that would be incurred by the building owner. Therefore, the maintainability of such materials in order to meet aesthetical and functional performance requirements should be easy with lesser requirements of cleaning and inspections $\left(9^{\text {th }}\right.$ risk factor $)$.

\subsection{Risk of Construction Quality}

The construction quality, also known as the workmanship, has been identified as one of the most crucial causes in building failures by many industry professionals ( $10^{\text {th }}$ risk factor). Findings from interviews carried out for this study highlighted the main issues on unskilled labourers and cost-driven contractors which led to negligence in workmanship. Further, the contractors should be encouraged to participate on the scheme so as to improve their quality and competitiveness to enhance the firms' image and professionalism. Clients and developers should also be encouraged to specify the use of accredited contractors for their projects to ensure the level of construction quality achieved. Therefore construction quality can be graded as,

$$
\text { Constructbn QualityScore }=\frac{C O_{F}+C O_{r, m h}+C O_{\mu N}+C Q_{4}}{4}
$$

$$
\begin{gathered}
\text { Where } \mathrm{CQ}_{\mathrm{F}} \quad \text { financial quality } \\
\mathrm{CQ}_{\text {Tech }} \quad \text { - } \\
\mathrm{CQ}_{\mathrm{HR} \text { - }} \quad \text { - }
\end{gathered}
$$


$\mathrm{CQ}_{\mathrm{U}} \quad$ - $\quad$ quality management

\subsection{Risk of Maintenance Practice}

All buildings deteriorate through aging under various exposure conditions. However, they have to maintain their performance throughout their design lives. The management of this process through corrective maintenance needs extensive capital expenditure. But, this should be minimized whilst ensuring maximum performance of buildings throughout its life. This involves the development of routine and preventive maintenance policies and procedures to plan for the repair and replacement of building components. In general, proper maintenance procedures should be able to upkeep the durability and the performance of the material. Therefore, flat roofs having a planned maintenance strategy that includes regular inspections, cleaning and corrective repair and replacement works can be awarded with a higher grading $\left(11^{\text {th }}\right.$ risk factor $)$.

\subsection{Risk of Building Profile}

A building's profile such as its age and height affects its maintainability. Low-rise buildings are assumed to take less effort in maintaining than tall buildings. The age of the building on the other hand may dictate the frequency of occurring defects. In addition, the durability of flat roof elements that have been repaired, in older buildings may require additional effort, compared with new buildings. Therefore, the height and age of a building should be factored in and adjusted in the determination of flat roof maintainability $\left(12^{\text {th }}\right.$ risk factor).

\section{Risk Management}

Risk management in the maintainability can be expressed as controlling of the LCC associated with the maintenance. In the maintainability risk management, avoiding or minimizing by adopting safety measures in the design, construction or even maintenance practices could control the LCC. In other words, the inherent maintainability risk should be carefully analysed and controlled to minimize the LCC associated with maintenance. Therefore, a model which can be used to indicate or predict the maintainability of buildings can be designed as a risk management tool. In this research, a model is developed to predict the level of maintainability of flat roofs which is estimated by analysing the existing risk conditions identified from the survey.

\subsection{Outline of the Proto-type Model}

To assess the level of maintainability, a model using multi-layered perceptron neural networks which is known by the name of the algorithm used to train it, back propagation, was developed. The model's framework was designed to compute the level of maintainability as an output in response to input parameters that reflect the severity of inherent risk of flat roof maintainability. Mathematically, it can be expressed as a mapping function:

$$
f_{E}: \Re \mapsto \mathrm{M}
$$

where domain $\Re$ is a set of $n^{\text {th }}$ dimensional vector $\left[r_{1}, r_{2}, . . r_{n}\right]$ of risk inputs representing a risk domain of the maintainability, and $\mathrm{M}$ is a set of scalars providing points to an underlying maintainability function.

\subsection{Input Risk Parameters}

In this model, 12 significant risk factors of flat roof maintainability as illustrated in Table 1 were taken as inputs to the network. The equation 4 summarises the quantification of risk factors.

Supposed that $K$ sets of sub-grades denoted by $\left[F_{n}\right]_{k}, m=1, \ldots M, k=\backslash, . . K$ is established to set the alternatives of each factor. The overall level of seriousness of a risk $R_{i}$ is then modeled by,

$$
R_{i}=\frac{\sum_{n=1}^{N} \sum_{m=1}^{M}\left(F_{m, k} \times A_{m}\right)_{n}}{N}
$$

where $F_{m_{\text {sn }}}$ denotes $k^{*}$ sub-grade of $m^{\text {th }}$ attribute (element)

$A_{m}$ is the area of coverage by $m^{\text {to }}$ element

$\mathrm{N}$ is the number of parameters of $i^{\text {th }}$ risk

factor

6.3 Level of Maintainability - The Output of the Model

The level of the maintainability was worked out based on the cost associated with maintenance activities such as repair, replacement and cleaning costs. The optimum level of maintainability was evaluated based on the minimum life cycle maintenance costs at a certain period [25], 


$$
M S=\backslash-\left[\frac{\sum_{i=1}^{m} R R D C_{i}+C C}{\sum_{i=1}^{M} R R D C_{i}+B C C}\right]
$$

where $m$ is the current number of defects/problems in a building, $M$ is total number of defects/problems in the building at the base period (Table 1), $R R D C_{i}$ is the respective repair and replacement costs of $i$ th defect/problem, $C C$ is actual cleaning cost and $B C C$ is the basic cleaning cost derived from required cleaning cycles.

\subsection{Network Design and Training}

Designing of the network is determined by three parameters; number of neurons in the input, hidden and output layers. However, the number of neurons in the input and output layers are predetermined by the size of the input and output vectors respectively. In this network, the number of nodes in these two layers were set as 12 and 1 respectively. Even though there is no exact rule for determining the optimum number of hidden nodes, it was found from the trial and error method that it should be between the average and sum of the input and output nodes. Furthermore, it is found that, the size of the hidden layer can be set according to the rule of thumb; $75 \%$ of the size of the input layer [30-31]. Among various architectures and paradigms, the most simplest and practicable network; backpropagation which has been used to perform higher level human tasks such as planning, scheduling and forecasting, etc., was used for the model. A set of 50 examples was fed into this feed forward network for training. This learning algorithm performs simple gradient descent, propagating the differences, or error $(E)$, back through the network to contribute a small adjustment to the each weight or bias parameters as,

$$
E=\frac{1}{2 P} \sum_{i=1}^{p}\left(D_{i j}-O_{j}\right)^{2}
$$

where $P$ is the number of training samples, $D_{i j}$ is the desired output value of the $i$ th processing element (neuron) to the $j$ th training example and $O_{j}$ is the corresponding output value.

In this process, the difference cf output activity pattern moves nearer to its global minima as,

$$
E=E+\frac{1}{2 P}(D-O)^{2}
$$

where $D$ is the desired output and $O$ is the computed output

The accuracy of the network was tested until the best network structure was established. The best results (Equation 7) were obtained from the network of one hidden layer that consists of 9 processing elements (PE) (Figure 1). The total number of 14,419 network cycles (epochs) were run to converge to the given target $\left(10^{-3}\right)$.

\subsection{Network Performance and Analysis}

Low approximation error (0.001) combined with low generalization error (0.0270) in the network ensures the best performance of the network. Such a paradigm ensures a good approximation with a smooth fitting over the training data and that smooth fitting leads to ensure best forecasting (generalization) of new data.

In the process of grading maintainability of a building, the network determines the level of maintainability associated to a particular design by analyzing its risk environment (i.e. input risk parameters) from "known" risks conditions that are derived from examples (cases) shown to the network during its training cycles.

The network was used to predict the maintainability of flat roofs in Sri Lanka. A typical case (Table 3 ) which represents a typical flat roof condition was tested. The results showed that the maintainability level was $51 \%$. This indicates that lots more could be done to improve flat roofs' performance to achieve high maintainable roofs in multi-story buildings in Sri Lanka. In general, water leaking problems due to lack of maintenance together with lack of waterproofing design detailing and poor performance of the concrete slab cause many maintainability problems. The need of an effective drainage system was too highlighted by many maintenance managers. Even with good drainage systems, they were not being properly maintained due to lack of allocation or no allocation of maintenance budget.

Misfortune of traditional construction process of many multi-story buildings in Sri Lanka is that niether maintenance person is employed nor budget is allocated for regular maintenance of a property. 


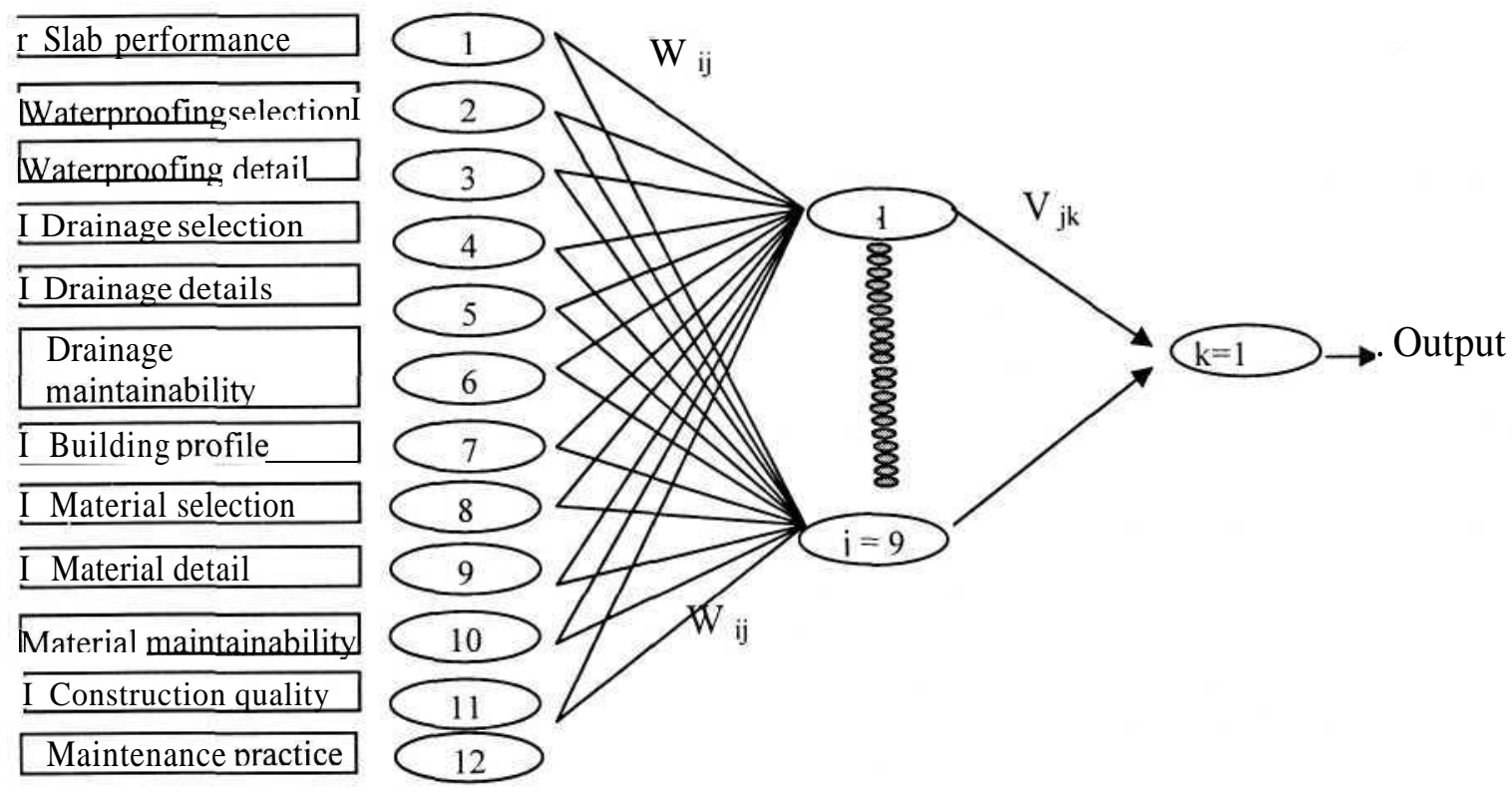

Figure 1: Architecture of the Network

Further, trained network was used to extract knowledge for the users to gain a better understanding of how the networks solve the problem. Pruning techniques uses to eliminate less important connections (nodes) from the networks is identified for this task [32-34].

According to this technique, the maximum error$£$ value indicates the highest sensitivity of the

Table 3: Risk Conditions of a Typical Roof Structure

\begin{tabular}{|l|c|}
\hline Risk Parameter & $\begin{array}{c}\text { Risk } \\
\text { Condition }\end{array}$ \\
\hline Slab Performance & 3.50 \\
\hline Waterproofing SystemSelection & 3.62 \\
\hline Waterproofing SystemDetail & 3.29 \\
\hline External Drainage System Selection & 3.44 \\
\hline External Drainage System Detail & 3.42 \\
\hline $\begin{array}{l}\text { External Drainagem } \\
\text { Maintainability }\end{array}$ & 3.20 \\
\hline Building Profile & 4.03 \\
\hline MaterialSelection & 3.58 \\
\hline MaterialDetail & 2.93 \\
\hline Material Maintainability & 3.10 \\
\hline Construction Quality & 3.27 \\
\hline Maintenance Practice & 3.26 \\
\hline
\end{tabular}

parameter to its desired accuracy. Having set that, observing the sensitivity of each factor in the training dataset can be determined the importance of the factor to function of the maintainability. Mean squared errors $(\varepsilon)$ of roof risk parameters obtained according the algorithm, showed all of 12 factors were significant to the flat roof maintainability. Among these factors, performance of the slab detailing have shown highest sensitivity to the network followed by waterproofing detailing, external drainage maintainability, etc., (Table 4)

\section{Conclusion}

The total number of randomly selected 50 buildings was used to evaluate the maintainability problems of flat roofs. The research revealed that the awareness of maintainability concept of buildings is very low and hence, maintainability issues related to building design, construction and maintenance are not yet taken up by the practitioners in the industry, in order to enhance the maintainability of buildings. However, this ignorance has created an escalating number of building defects and problems with increased number of multi-storey buildings. In flat roofs of 50 buildings, 721 defects/problems were observed. Among them cracks, chockages in down pipes and splitting were ranked as first, second and third defects respectively. 
Table 4: Sensitivity Analysis of Risk Inputs

\begin{tabular}{|l|c|c|}
\hline RiskFactors & MSE $(\varepsilon)$ - maximum & Rank \\
\hline $\begin{array}{l}\text { performance of the detailing of } \\
\text { the slab }\end{array}$ & 8.7 & 1 \\
\hline waterproofing detailing & 6.7 & 2 \\
\hline $\begin{array}{l}\text { external drainage system } \\
\text { maintainability }\end{array}$ & 4.6 & 3 \\
\hline building profile & 3.9 & 4 \\
\hline material maintainability & 3.6 & 5 \\
\hline maintenance practices & 2.9 & 6 \\
\hline external drainage system & 2.7 & 7 \\
\hline waterproofing system & 2.6 & 8 \\
\hline material selection & 2.2 & 9 \\
\hline construction quality & 1.9 & 11 \\
\hline material detailing & 1.4 & 12 \\
\hline external drainage detailing & 1.2 & 13 \\
\hline
\end{tabular}

This model which is developed based on maintenance cost approach would eventually be used to guide the maintenance requirements of flat roofs during the design stage. Further, as a predictive tool, this system would enable owners, designers, facility managers, contractors and any other party with an interest in achieving the most favourable maintainability level right from the design/planning stage.

The accuracy of this ANN model developed for flat roof was tested. The low network error and the generalization error indicated the good performance of the network and its capability of predicting levels of maintainability for new designs. The trained network error was used to evaluate the maintainability level of a typical case study. A fifty one percent level was observed and therefore more consideration is needed to enhance the level of maintainability.

Further, it is useful to identify important considerations in roof maintainability. Therefore, the sensitivity of all risk parameters towards affecting level of maintainability for flat roofs was evaluated. The extraction of the knowledge embedded in a trained network is a comprehensive way for designers to understand the function through the sensitivities of the inputs. An algorithm which was established using the pruning concept was used to identify the sensitivity of these individual inputs to the function of maintainability. This sensitivity analysis showed that the maintainability of flat roofs relies very much on its,

o Performance of structural elements

o Detailing of waterproofing being applied

o Maintainability of external drainage system

o Building profile
- Materials performance such as maintainability and durability and,

- Maintenance practices

o Construction quality

\section{References}

1. De Silva, N., Dulaimi, M.F., Ling, F.Y.Y and Ofori, G. (2004) Improving the maintainability of buildings in Singapore, Building Research \& Information, 39(10), 1243-1251.

2. Seely, I. H. (1994) Building Maintenance, $2^{\text {nd }}$ ed. Macmillan Press Ltd: London.

3. Wood, B. (2005) Towards innovative building maintenance, Structural Survey, 23(4), 291-297.

4. Boussabaine, A.H. and Kirkham, R.J. (2004) Simulation of maintenance costs in UK local authority sport centers, Construction Management and Economics, 22(1), 1011-1020.

5. Al-Hammad, A., Assaf, S. and Al-Shihah, M. (1997) The effect of faulty design on building maintenance, Journal of Quality in Maintenance, 3(1), 29-39.

6. Shohet, I.M., Puterman, M. and Gilboa, E. (2002) Deterioration patterns of building cladding components for maintenance management, Construction Management and Economics, 20, 305314.

7. www.statistics.gov.lk, accessed on 18th July 2007.

8. Gambardella, L M and Moroni, M (1990) Expert systems application to building pathology diagnosis: methodology, Proceeding of the Second European Conference on Application of Artificial Intelligence and Robotics to Building, Architecture and Civil Engineering, EuropIA 90, Liege, Belgium, 252258.

9. Honstede, W.V. (1990) Research into the quality of housing stocks in the Netherlands, Building Maintenance and Modernization Worldwide, 2, 659668.

10. Assaf, S., Al-Hammad, A. and Al-Shihah, M. (1995) The Effect of Faulty Construction on Building Maintenance, Building Research and Information, 23, 175-81. 
11. Olubodun, O. F. (1996) An empirical approach to the evaluation of factors in local authority housing maintenance requirements in the city of Manchester, Unpublished PhD Thesis, University of Salford.

12. Bourker, K. and Davies, H. (1997) Factors affecting the service life predictions of buildings: a discussion paper, Laboratory Report, Building Research Establishment, Garston, UK.

13. Meier, J. R. and Russell, J. S. (2000) Model process for implementing maintainability, Journal of Construction Engineering and Management, 126(6), 440-450.

14. Stephen, J.H., (2002). Building Services MaintenanceThe Forgotten Discipline. Aha Management Publications; www.aha.com.au/energyl.htm, accessed on $25^{\text {th }}$ August 2007

15. Chew, M.Y.L. and De Silva, N. (2003) Maintainability problems of wet areas in high-rise residential buildings, Building Research \& Information, 31(1), 60-69.

16. Chew, M.Y.L. and Tan, P.P. (2003). Facades staining arising from design features, /. Construction and Building Materials, 17(3), 181-187.

17. Newton, L.A. and Christian, J. (2006) Impact of quality on building costs, Journal of Infrastructure Systems, 12(4), 199-206.

18. Shabha, G. (2003) A low cost maintenance approach to high rise flats, Facilities, 21(13/14), 315-322.

19. Hermans, M.H. (1995) Deterioration Characteristics of Building Components: A Data Collection Model to Support Performance Management, Eindhoven, TU Eindhoven.

20. Straub, A. (2003) Using a condition-dependent approach to maintenance to control costs and performance, Journal of Facilities Management, 1(4), 380-95.

21. Chew, M.Y.L. and De Silva, N. (2004) Factorial method for performance assessment of building facades, \% Construction Engineering and Management, 130(4), 525-533.

22. Teo, E. A. and Harikrishna, N. (2006) A quantitative model for effective maintenance of plastered and painted façades, Construction Management and Economics, 24, 1283-1293.

23. Tesfaye, A. (1997) A holistic approach towards low maintenance buildings: a case study of sample residential buildings in Botswana, Proceedings of $5^{\text {th }}$ International Conference on Inspection, Appraisal, Repairs and Maintenance of Buildings and Structures, 15-16 May 1997, Singapore.

24. Chanter, B. and Swallow, P. (2000) Building Maintenance Management, Blackwell, Oxford.

25. Chew, M.Y.L., De Silva, N. and S.S. Tan (2003) Maintainability of buildings in the tropics, CIB International Workshop on Management of Durability in the BuildingProcess, Politecnico di Milano, Italy.

26. De Silva, E.N.D. (2000) Allocation of Contingency and its Managementfor Construction Costs in Singapore: A Probabilistic Approach Using ANN, Unpublished Master of Science Thesis, University of Singapore.

27. Lisboa, P.G.J. (1992) Neural Networks Current Applications, Chapman \& Hall, London.

28. Ian, F. and Nabil, K. (1998) Artificial Neural Networks for Civil Engineers: Advanced Features and Applications, ASCE, Reston, VA.
29. Haykin, S. (1999) Neural Networks: A Comprehensive Foundation, Second Edition, Prentice Hall, Upper Saddle River.

30. Bailey, D. and Thompson, D. (1990) How to develop neural network applications, AI Experts, 5(6), 38-47.

31. Goh, B H (2000) Evaluating the performance of combining neural networks and genetic algorithms to forecast construction demand: the case study of the Singapore residential sector, Construction Management and Economics, 18(2), 209-217.

32. Zurada, J.M., Malinowski, A. and Cloete, I. (1994) Sensitivity of minimization of input data dimension for feedforward neural networks, IEEE International Symposium on Circuits and Systems, London.

33. Rudy, S. (1997) Extracting rules from neural networks by pruning and hidden-unit splitting, Neural Computation, 9(1), 205-225.

34. Chew, M.Y.L., De Silva, N. and S.S. Tan (2004) "A neural network approach to assessing building façade maintainability in the tropics," Construction Management and Economics, 22(6), 581-594. 